\title{
The Acceptance of Using Library Mobile Application of the Students at Faculty of Liberal Arts, Rajamangala University of TechnologyThanyaburi
}

\author{
Wannaya Chaloeyprach ${ }^{1}$, Montchatry Ketmuni ${ }^{2}$ \\ ${ }^{1,2}$ Faculty of Liberal Arts, Rajamangala University of Technology Thanyaburi, Thailand, \\ 1wannaya_c@rmutt.ac.th, ${ }^{2}$ montchatry@rmutt.ac.th
}

\begin{abstract}
This research was funded by Institute of Research and Development, Rajamangala University of Technology Thanyaburi. The purposes of this exploratory research were 1) to identify students' level of the acceptance toward the use of the library mobile application, 2) to examine factors influencing the students' level of the acceptance toward the use of the library mobile application, 3) to investigate the students' satisfaction toward the use of the library mobile application, and 4) to suggest some guidelines for future development of the library mobile application at Faculty of Liberal Arts, Rajamangala University of Technology Thanyaburi (RMUTT). The 400 students of Faculty of Liberal Arts, RMUTT, who used the library service, were selected by convenience sampling. The research instrument was a questionnaire $($ IOC $=0.977, \alpha=0.970)$. The data were analyzed by percentage, mean, standard deviation, t-test, f-test, Pearson's correlation coefficient, and multiple regression. The research results showed that the students' acceptance toward the use of the library mobile application was at high level $(=3.93)$ : attitude ( $=4.01$ ), perceived usefulness $(=3.93)$, perceived ease of use $(=3.91)$, and intention to use $(=3.86)$. The overall satisfaction of the students toward using the library mobile application was at high level ( =3.86). According to hypothesis testing, the differences of frequency of use, objectives of use, getting advice, and learning how to use the library mobile application affecting the students' acceptance of using library mobile application at the level of .05 statistically significant difference. The multiple regression analysis could predict the acceptance of using the library mobile application that perceived ease of use, perceived usefulness, attitude, and satisfaction affected intention to use. In order to increase the performance of the library mobile application, the students suggested that the library mobile application manual in Thai language should be provided, online user support should be available via the application, and full text should be able to be downloaded
\end{abstract}

Index Terms

Technology Acceptance Model (TAM), Library Mobile Application, Academic Library

Article Received: 10 August 2020, Revised: 25 October 2020, Accepted: 18 November 2020

\section{Introduction}

Currently, information technology and communication are rapidly evolved and used to connect people from all over the world. The information can be easily and immediately accessed anywhere and anytime [1][2], and systematically retrieved via mobile devices, such as smartphones, netbooks, tablet, etc. Smartphones are the popular device because of modern design, light weight, easy portable, and compatibility with many application programs. In addition, low pricing causes more purchasing and more mobile usage [3].According to mobile usage statistics during $2013-2017$ in Thailand, computer usage declined from $35 \%$ to $30.8 \%$, whereas internet usage increased from $28.9 \%$ to $52 \%$ as well as a number of mobile consumers increased from $73.3 \%$ to $88.2 \%$ and the internet was accessed via smartphones by $93.7 \%$, via computers by $25.4 \%$, via notebooks by $20.0 \%$, via tablets by $10.2 \%$ [4].According to these statistics, it indicates that mobile technology is popular and widely used. The technological advances of smartphones changes consumption behaviors. Ease and speed of service are needed for online services like online shopping, making a reservation, conducting online transactions, finding a location and navigation, reading online e-books, and using online library resources [5][3]; hence, many organizations try to develop mobile applications to facilitate their customers.

The Library of Faculty of Liberal Arts, Rajamangala University of Technology Thayaburi (RMUTT), Thailand realized the importance of integration of technology into library services, and the necessity of offering library services on a mobile application for academic engagement and achievement. Thus, the Library of Faculty of Liberal Arts, RMUTT procured a library application for book renewal, information retrieval, book reservation, book recommendations, and notification for loan expiring in order to derive the students' satisfaction. As the researcher and librarian, I roughly asked some students who used the library mobile application and it found that they were interested in and satisfied with the library mobile application because they could renew their books at home when they had no classes. They could retrieve and reserve the books they wanted. However, some students did not accept the library mobile application because they liked to find and borrow the books by themselves. Some said their phones were nearly running out of memory, so they did not want to download any applications. Some said they preferred using the library program on a computer to on a mobile phone, and they did not know how to use the library mobile application. According to [6], there are both skilled and unskilled users. The differences of mobile device skills are one of the obstacles to service development through mobile devices. The important problem is the new innovation acceptance of the library users, so the Library needs to let the users accept the information services on mobile phone in terms of usefulness, convenience, and ease and speed of use. If the users accept these reasons, the implementation of the library services on mobile phone will be successful.

In addition, factors in the information technology acceptance are great significant to explain the users' 
technology acceptance in daily life comprising perceived usefulness, perceived ease of use, attitude toward using, intention to use and actual use [7].The study of [8],titled User Acceptance of Mobile Library Applications in Academic Libraries: An Application of the Technology Acceptance Model, brought the Technology Acceptance Model (TAM) to study the users' acceptance of library mobile applications and it found that perceived usefulness, interactivity, and ease of use affected users' attitude and intention to use mobile library applications, and users' satisfaction also affected intention to use. Another research of [9] studied about the awareness and used of smartphone applications to the available services of the University of Bahrain Library, and its results indicated that students positively accepted using the library application and information services and would intend to use if the system was effective and able to access various information and services on mobile phones.

\section{Research Objectives}

The objectives of this research were 1) to identify students' level of the acceptance toward the use of the library mobile application, 2) to examine factors influencing the students' level of the acceptance toward the use of library mobile application, 3) to investigate the students' satisfaction toward the use of library mobile application, and 4) to suggest some guidelines for future development of the library mobile application at Faculty of Liberal Arts, RMUTT, Thailand.

\section{Research Methods}

\section{A. Research Design}

This quantitative research was conducted on 400 undergraduate students of Faculty of Liberal Arts, RMUTT, Thailand in the first semester of academic year 2019. The samples are sized by Taro Yamane's method and selected by convenience sampling. The research instrument used was the 5 Likert's scale questionnaire with Index Objective Congruence (IOC) of 0.977 and the reliability of Cronbach's alpha coefficient at 0.970 . The data obtained were analyzed by using the descriptive statistics of percentage, average value, standard deviation, and hypotheses were tested by independent sample t-test, f-test with LSD, Pearson's product moment correlation coefficient, and multiple regression with enter method.

\section{B. Research Process}

Research process of this research has developed into 5 steps consisted of to intensive literature review, created research tools, conduct the experiment, assess experimental results, and to develop concluding remark Steps were shown in Fig. 1.

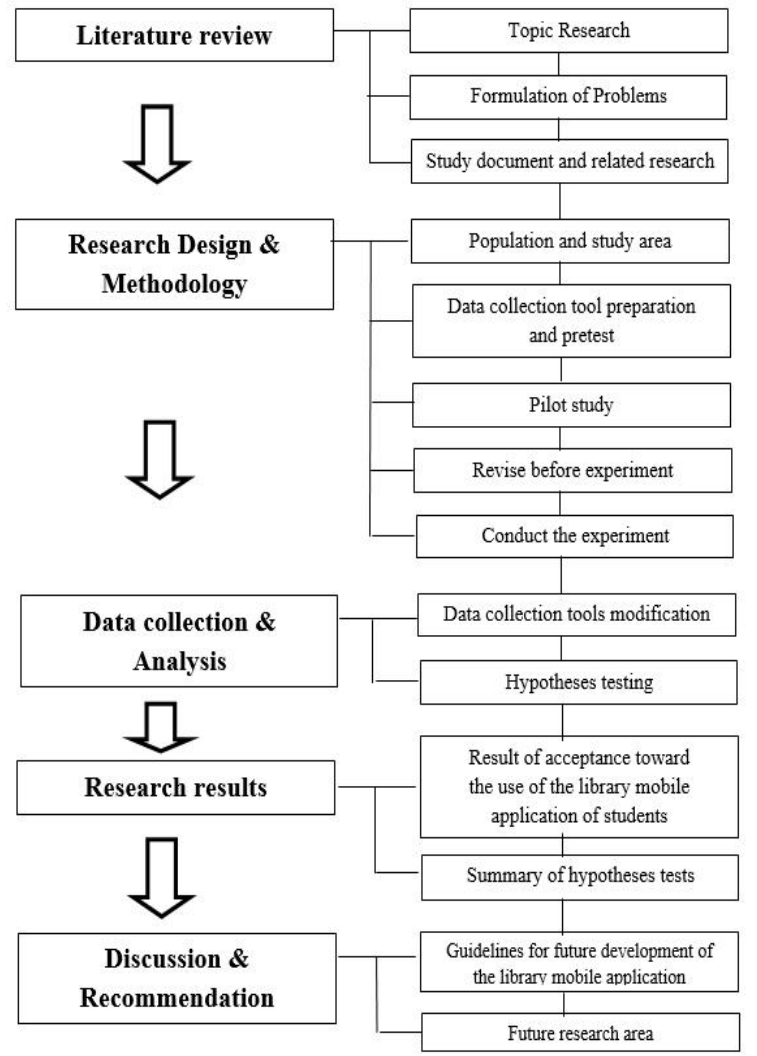

Fig.1 A flow diagram of the detailed research process

\section{Results}

The research results showed that the students' new technology acceptance of library services by using mobile application at Faculty of Liberal Arts, RMUTT was at a high level $(\overline{\mathrm{X}}=3.93)$. Considering each aspect of the Technology Acceptance Model (TAM), the students accepted using the library mobile application at a high level in all aspects. The average of each aspect could be arranged in descending order as follows: attitude $(\overline{\mathrm{X}}=4.01)$, perceived usefulness $(\overline{\mathrm{X}}=3.93)$, perceived ease of use $(\overline{\mathrm{X}}=3.91)$, intention to use $(\bar{X}=3.86)$. Regarding the students' satisfaction toward the library mobile application, the level of the overall satisfaction was high $(\overline{\mathrm{X}}=3.86)$ when $\mathrm{QR}$ code service for downloading the library mobile application $(\overline{\mathrm{X}}=4.32)$ was the most satisfaction following by the usefulness of the library mobile application (the library mobile application was useful in daily life, such as, time saving, reducing travel expenses, etc. $(\overline{\mathrm{X}}=4.10)$, and the library mobile application working as expected $(\overline{\mathrm{X}}=4.09)$.

The research hypotheses were tested of the significance of correlation efficient that could be summarized as follows:

H1: The students' differences of using library mobile application differently influenced the acceptance toward the use of the library mobile application at statistically significant difference of .05 . The students' differences of using library mobile application could be categorized as frequency of use, objectives of use, getting advice, and resources to learn about the library mobile application usage as shown in Table 1. 
Table 1 The students' differences of using library mobile application differently influenced the acceptance toward the use of the library mobile application

\begin{tabular}{|c|c|c|c|c|c|c|}
\hline The use of the library mobile application & $\mathbf{n}$ & $\overline{\mathrm{X}}$ & S.D. & $\mathbf{F}$ & df & p \\
\hline \multicolumn{7}{|l|}{ Frequency of use } \\
\hline 1 time / a week & 59 & 3.94 & 0.44 & 4.353 & 263 & $0.000^{*}$ \\
\hline 2-3 times / a week & 142 & 4.06 & 0.39 & & & \\
\hline 4-5 times / a week & 48 & 4.03 & 0.38 & & & \\
\hline More than 5 times / a week & 25 & 3.87 & 0.31 & & & \\
\hline Occasionally & 126 & 3.75 & 0.93 & & & \\
\hline Objectives of use & n & $\overline{\mathrm{X}}$ & S.D. & $\mathbf{F}$ & df & p \\
\hline For book search & 208 & 4.07 & 0.43 & 6.107 & 263 & $0.000^{*}$ \\
\hline For book renewal & 72 & 3.95 & 0.38 & & & \\
\hline For checking book return due dates & 61 & 4.24 & 0.22 & & & \\
\hline For checking alert messages & 59 & 3.08 & 0.95 & & & \\
\hline Getting advice & n & $\overline{\mathrm{X}}$ & S.D. & $t$ & df & p \\
\hline Never & 295 & 4.13 & 0.36 & 9.298 & 118 & $0.000^{*}$ \\
\hline Ever & 105 & 3.36 & 0.83 & & & \\
\hline Learning how to use the library mobile application & n & $\overline{\mathrm{X}}$ & S.D. & $\mathbf{F}$ & df & $\mathbf{p}$ \\
\hline Librarian & 190 & 4.12 & 0.38 & 2.019 & 263 & $0.000^{*}$ \\
\hline Teachers & 44 & 3.62 & 0.81 & & & \\
\hline Friend & 47 & 3.30 & 0.97 & & & \\
\hline Self-study & 82 & 3.90 & 0.50 & & & \\
\hline Library Facebook & 37 & 4.14 & 0.353 & & & \\
\hline
\end{tabular}

H2: The students' acceptance toward the use of the library mobile application positively related to the students' satisfaction toward the use of the library mobile application at the level of .05 statistical significance. This confirmed the hypothesis that the students' acceptance toward the use of the library mobile application related to the students' satisfaction toward the use of the library mobile application. Considering each factor of TAM, the results would be summarized to confirm 7 hypotheses as follows:

H2.1: Perceived ease of use (PEOU) highly related to

Perceived usefulness (PU) $(r=0.717)$.

$\mathrm{H} 2.2$ : Perceived usefulness (PU) moderately related to

Attitude of use (ATU) $(\mathrm{r}=0.666)$.

H2.3: Perceived ease of use (PEOU) moderately related

to Attitude of use (ATU) $(r=0.666)$.

$\mathrm{H} 2.4$ : Perceived usefulness (PU) highly related to

Intention to use (ITU) $(\mathrm{r}=0.833)$.

$\mathrm{H} 2.5$ : Perceived ease of use (PEOU) highly related to

Intention to use (ITU) $(r=0.733)$.

H2.6: Attitude of use (ATU) highly related to Intention to use (ITU) $(r=0.799)$.

H2.7: Satisfaction (ATU) highly related to Intention to use (ITU) $(r=0.799)$.

The correlation between the students' acceptance and satisfaction toward the use of the library mobile application was shown in Table 2.

Table 2 The correlation between the students' acceptance and satisfaction toward the use of the library mobile

\begin{tabular}{lccccc}
\multicolumn{1}{c}{ application } & & & \\
\multicolumn{1}{c}{ Constructs } & PU & PEOU & ATU & ITU & SA \\
\hline Perceived usefulness (PU) & 1.000 & & & & \\
Perceived ease of use (PEOU) & $0.717^{* *}$ & 1.000 & & & \\
Attitude of use (ATU) & $0.666^{* *}$ & $0.610^{* *}$ & 1.000 & & \\
Intention to use (ITU) & $0.833^{* *}$ & $0.733^{* *}$ & $0.799^{* *}$ & 1.000 & \\
Satisfaction (SA) & $0.599^{* *}$ & $0.694^{* *}$ & $0.622^{* *}$ & $0.724^{* *}$ & 1.000 \\
\hline
\end{tabular}

${ }^{* *} \mathrm{p}<.05$.

Multiple regression with enter method was then applied to this research for hypothesis testing and the results were shown as follows:

$\mathrm{H}$ 2.1: Perceived ease of use (PEOU) influenced

Perceived usefulness (PU) $(\beta=0.717, \mathrm{p}<.05)$.

$\mathrm{H}$ 2.2: Perceived usefulness (PU) influenced

Attitude of use (ATU) $(\beta=0.471, \mathrm{p}<.05)$.

$\mathrm{H} 2.3$ : Perceived ease of use (PEOU) influenced
Attitude of use (ATU) $(\beta=0.272, \mathrm{p}<.05)$.

$\mathrm{H} 2.4$ : Perceived usefulness (PU) influenced

Intention to use (ITU) $(\beta=0.633, p<.05)$.

H2.5: Perceived ease of use (PEOU) influenced

Intention to use (ITU) $(\beta=0.278, p<.05)$.

H2.6: Attitude of use (ATU) influenced Intention to use

(ITU) $(\beta=0.799, \mathrm{p}<.05)$.

H2.7: Satisfaction (ATU) influenced Intention to use (ITU) $(\beta=0.724, \mathrm{p}<.05)$.

According to Table 3, the influence of each factors could be represented as Fig 2.

Table 3 Summary of hypotheses tests

\begin{tabular}{|c|c|c|c|c|}
\hline Hypotheses & $\beta$ & $\mathbf{t}$ & $\mathbf{P}$ & Results \\
\hline H1: PEOU $\gg \gg$ PU & 0.717 & 20.548 & $0.000^{*}$ & Accepted \\
\hline H2: PU $\gg>$ ATU & 0.471 & 9.070 & $0.000^{*}$ & Accepted \\
\hline H3: PEOU $\gg>$ ATU & 0.272 & 5.238 & $0.000^{*}$ & Accepted \\
\hline H4: PU $\gg>$ ITU & 0.633 & 16.962 & $0.000^{*}$ & Accepted \\
\hline H5: PEOU $\gg \gg$ ITU & 0.278 & 7.458 & $0.000^{*}$ & Accepted \\
\hline H6: ATU $\gg>>$ ITU & 0.799 & 26.541 & $0.000^{*}$ & Accepted \\
\hline H7: SA $\gg>$ ITU & 0.724 & 20.947 & $0.000^{*}$ & Accepted \\
\hline
\end{tabular}

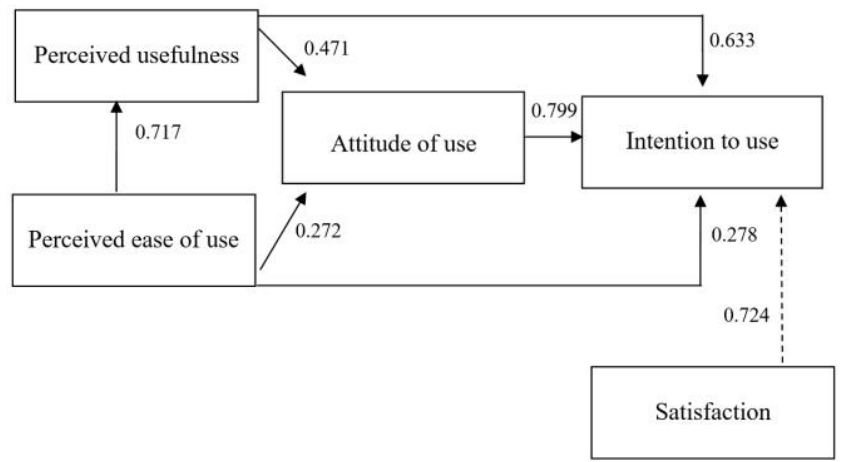

Fig.2 The influence of each factor

\section{Discussions}

1. The students' differences of using library mobile application differently influenced the acceptance toward the use of the library mobile application by the frequency of use, objectives of use, getting advice, and resources to learn about the library mobile application usage. The results from comparing the data showed that the students using the library mobile application 2-3 times a week for book search, book renewal, and checking book return due dates and learning how to use the library mobile application from the librarian and the Library Facebook had the acceptance higher than the students occasionally using the library mobile application for checking alert messages and learning how to use the library mobile application from teachers and on their own. The students who accepted the use of the library mobile application at the high level would realize the benefits of using the library mobile application meeting their needs, for example, renewing books from anywhere, easily using the library mobile application with no effort required and uncomplex system, and getting good advice from the librarian. This leaded to more frequent library mobile application usage, greater satisfaction, positive attitude, and then actual use. This is consistent with the study of [10]found that the graduate students accessing the e-Thesis database with web mobile technology retrieved the information on the Digital Collection database at the highest 
level due to ease of use, simplicity, getting satisfying results. Therefore, these resulted in positive behaviors and attitude toward using then leading to high frequency of accessing the database.

2. Factors influencing the library mobile application of the students at Faculty of Liberal Arts, Rajamangala University of Technology Thanyaburi could be discussed as follows:

$2.1 \mathrm{H} 1$ : Perceived ease of use influenced perceived usefulness resulting from the menu interface that made the library mobile application easy to retrieve books and access the library information. Students could learn how to use the library mobile application quickly, without effort required, and ubiquitously. In addition, the book renewal menu provided convenience to the students coming to the library in person resulting in time saving and reducing travel expenses. Therefore, this led to the students' acceptance of using the library mobile application. [11] noted that the ease of use with no complexity of technology affected perceived usefulness and it is correlated with the study of [12] that perceived ease of use of e-Learning had the direct effect on perceived usefulness and correlated with [13] that perceived ease of use affected perceived usefulness. The learners perceived the usefulness of learning language through the mobile application because the mobile application could get along with the learners' lifestyle and time management including having fun, providing entertainment, and attracting the learners' attention, then the learners could perceive the usefulness of learning through the mobile application.

2.2 H2: Perceived usefulness influenced attitude to use the library mobile application; this was because the library mobile application could support the library services, for example, book retrieval, self-check borrowing information, book renewal, book reservation, late book fine payment, checking library hours, etc. These useful services led to the students' positive attitude to use the library mobile application and realized that the library mobile application was useful in their daily life, and then brought to the technology acceptance. This is consistent with the study of [14] that perceived usefulness of technology was the individual attitudes leading to technology acceptance or rejection. Perceived usefulness of the technology user created the intention to use the services. According to the previous research, [8] noted that perceived usefulness of the library mobile application users influenced the attitude to use.

2.3 H3: Perceived ease of use influenced attitude to use the library mobile application. The students perceived ease of use when they learned how to use the library mobile application by first-hand experience that built the positive attitude later on. [15] and [16] in their studies described that if the users perceived ease of use, they would be openminded and accept the technology. Thus, perceived ease of use is the factor influencing the positive attitude. These studies were consistent with that of [8] that the students' perceived ease of use influenced attitude to use and [12] found that perceived ease of use directly influenced attitude to learn e-Learning that led to the acceptance of e-Learning. 2.4 H4: Perceived usefulness influenced intention to use the library mobile application. Using the mobile application for library services allowed the students to be able to quickly access the library services. A due date reminder notification service could prevent the overdue fine and could save time for traveling to the library in person. That is why the students accept and intend to use the library mobile application. The results of this research also showed that the students were open minded to learn a new system and insisted on continuing to use the application. [17] noted that the technology acceptance led to actual use when the users were confident that the technology they used were useful. It is consistent with the study of [18] that although the users have never used the application, they would continue to use the application. That is why the useful information would exist and keep developing. According to [9], their study found that the users accepted using the library mobile application at a high level and would intend to use it if the library and developer worked together to design the effective application. This is supported by the study of [19] that perceived usefulness influenced intention to use the library mobile application, and by the study of [20] that the factor influenced intention to use the library mobile application was perceived usefulness as well as the study of [8] and [21] showed that the students' perceiving usefulness of the library mobile application would influence intention to use.

2.5 H5: Perceived ease of use influenced intention to use the library mobile application. The students perceived the ease of use, then they could quickly learn and use the application. With not much of an effort, they consequently intend to use the application. [22] noted that the intention to use the technology could be measured by perceived ease of use. In addition, perceived ease of use influenced intention to use; this is consistent with the studies of [19], [23],[20],[8], and [21].

2.6 H6: Attitude influenced intention to use the library mobile application. Ease of use the application led to the actual use, then the students had positive attitudes. This is consistent with the Technology Acceptance Model (TAM) [24]: perceived usefulness and perceived ease of use are the factors relating to attitude and intention to use. Attitudes toward intention to use affect the behaviors toward using the technology that are brought to accept or reject the technology acceptance. Because the students perceived that the application was easy to use and saved time for traveling to the library, the students were open-minded and intended to use the application. This is consistent with the study of [25] that perceived ease of use, perceived usefulness, and social factors influenced attitudes toward online social media; these attitudes influenced intention to use online social media. Furthermore, the study of [26] found that attitude influenced behaviors toward intention to use information service via mobile phone.

2.7 H7: Satisfaction influenced intention to use the

library mobile application. The expected library services on a mobile phone, such as information retrieval and book renewal, got the students satisfied, and the benefits of the application let the students accept the use of the library mobile application in daily life [27]. According to the study of [28], the technology integrated with service system development could build up the user satisfaction. When the services met the user expectations, it would serve the customer satisfaction [29]. This is related to [20] that the main factor affecting intention to use was the service 
quality, so the services via a mobile application had to be developed by the user's needs, for example, ask a Librarian, OPAC resource retrieval, online bibliography, short message service, etc. [8] found that the users were satisfied with the library mobile application at high level and the application affected intention to use. Moreover, [23] found that the satisfaction influenced the intention to use the library mobile.

\section{Recommendations}

\section{A. Recommendations for Practices}

1. According to the research results, the students accepted the library mobile application in terms of perceived usefulness at a high level because of time saving. For this reason, the library mobile application should be developed to improve efficiency by adding more features, such as full text download, user guide in Thai language, instant messaging in order to get the most out of the library mobile application, then the students can organize or plan their time.

2. The students accepted the library mobile application in terms of perceived ease of use at a high level because it was easy to search books and access electronic resources. So, there should be various information resource accessibility provided, such as OPAC, single search, or any kinds of searches connecting with various kinds of electronic resources in order to quickly access the resources the students are looking for.

3. The results found that the students accepted the library mobile application in terms of attitude to use at a high level: benefits for everyday life, and the app every student at the Faculty of Liberal Arts should have. Therefore, library mobile application usage guides should be provided, and the library mobile application should be advertised for raising awareness and convincing the students to use the library mobile application.

4. The students accepted the library mobile application in terms of intention to use at a high level because they were open-minded to use the library mobile application and insisted to continue using the library mobile application. Because of this, the library mobile application services should be improved to be easy to use, simple, multifunctional, and responsive to the students' needs in order to make the library mobile application more active. This development will let the students perceive the usefulness of the library mobile application that influences the positive attitudes to use and finally leads to actual use.

\section{B. Recommendations for Further Research}

1. The further research of needs and problems for the library mobile application usability should be conducted as qualitative research in order to improve the library mobile application meeting the students' needs.

2. The further research may be conducted with factor analysis of the acceptance of the library mobile application. The results would be the powerful development approach of the effective mobile application, and the guidelines for developers and designers to make the library mobile application more useful and more satisfying.
3. The further research may be conducted with other samples, for example, administrators, mobile application developers, librarians, and representatives of mobile application development companies in order to study different perspectives. Problems and solutions from the research would be a guideline to improve the library mobile application to be more effective.

\section{Conclusion}

The modern mobile technology nowadays has been developed and rapidly changed, and it leads to versatile uses in everyday life. The library services can adapt this technology to facilitate the users to effectively access the library resources. However, the library mobile application needs to support the users' behaviors in order that the users intend to use it and perceive its usefulness until they accept the new technology and are satisfied with the library mobile application. According to the research results of this research showing that the students accepted the library mobile application, the library mobile application developers could use the results as a guideline for building the effective library mobile applications with newer mobile technology in the future to support the needs of library users in order to increase the users' satisfaction.

\section{References}

[1] S. Singh and S. Malik, "Use of Mobile Technology in University Libraries: A Case Study of Maharaja Jiwaji Rao Library, Vikram University, Ujjain (M.P.)". In 2018 5th International Symposium on Emerging Trends and Technologies in Libraries and Information Services (ETTLIS 2018), pp.235-239. New Jersey: the Institute of Electrical and Electronics Engineers, Inc., 2018.

[2] W.Chanthara and S. Rungmee, "Library Applications : The Unstoppable Force", Journal of Humanities and Social Sciences, Thaksin University, Vol.11, No.3, pp. 73-88, 2016

[3] S. Wongchalee and S. Suwannapak, "MLibrary", Journal of Library and Information Science Srinakharinwirot University, Vol.3, No.4, pp. 141-147, 2012..

[4] Dailynews, "Survey Result of Use Smartphone instead Computer of Thai People", Retrieved on 17th March 2019, from https://www.dailynews.co.th/it/619622 
[5] A. S. Mishra, J. K. Jha and S. K. Umre, "Mobile App and The Library Services". International Journal of Information Libraries and Society, Vol.6, No.1, pp. 2732, 2017.

[6] K. Kwiecien, "Using of Mobile Technology for Information Services Development", Journal of Library and Information Science Srinakharinwirot University, Vol.6, No.1, pp. 95-102, 2013.

[7] A. Z-C. Chu, and R. J-C. Chu, "The Intranet's Role in Newcomer Socialization in Hotel Industry in Taiwan-technology Acceptance Model Analysis", [Electronics version], The International Journal of Human Resource Management, Vol.22, No,5, pp.1163-1179, 2011.

[8] Y. Hye-Young, "User Acceptance of Mobile Library Applications in Academic Libraries: An Application of the Technology Acceptance Model", The Journal of Academic Librarianship, Vol.42, pp.687-693, 2016.

[9] A. H. Abdulrazzaq and M. Al-Ani, "The Awareness and Use of Smartphone Applications to the Available Services of the University of Bahrain Library: A Proposed Application", Journal of WEI Business and Economics, Vol.7, No.1, pp. 22-32, 2018.

[10] S. Trivittayasiln, "Factors Affecting Adoption Behavior of the Web Mobile Access, The e-Thesis Database Access Technology", Humanities Journal (Graduate School) Ramkhamhaeng University, Vol.4, No.1, pp. 48-59, 2015.

[11] V. Venkatesh and F. D. Davis, A "Theoretical Extension of The Technology Acceptance Model: Four Longitudinal Field Studies", Management Science, Vol.46 No.2, pp.186-204, 2000.

[12] T. Kulsawat, "The Acceptance of ELearning among Undergraduate Students of Burapha University", Veridian EJournal,Silpakorn University (Humanities, Social Sciences and arts), Vol.7, No.1, pp. 308-320, 2014.
[13] C. Chaisamrong, "Acceptanceof Language Learning Technology Through Online Applications Of Consumers in Bangkok Metropolitan Region", Journal of Information Systems in Business (JISB), Vol.5, No.2, pp.25-42, 2019.

[14] W. Nurittamont, "Understanding the Role of Technology acceptance influence on internet banking intention: An empirical study in consumer of commercial bank", International Journal of Applied Computer Technology and Information Systems, Vol.6, No.2, pp.28-33, 2017.

[15] N. Jahangir and N. Begum, "The role of perceived usefulness, perceived ease of use, security and privacy, and customer attitude to engender customer adaptation in the context of electronic banking", African Journal of Business Management, Vol.2, No.1, pp, 32-40, 2008.

[16] P.Y.K. Chau, and V.S.K. Lai, “An empirical investigation of the determinants of user acceptance of internet banking", Journal of Organizational Computing and Electronic Commerce, Vol.13, No.2, pp.123-145, 2003..

[17] S.Tansupong, "Factors Influencing the Adoption of LINE Application", Master's dissertation, Graduate School, Bangkok University, Thailand, 2014.

[18] J. Changthong, "Mobile technology and information services: Perception of users", Journal of Humanities and Social Sciences Review (JHSSR) Phetchaburi Rajabhat University, Vol,16, No.2, pp.1-9, 2014

[19] H. Rafique and others, "Investigating the Acceptance of Mobile Library Applications with an Extended Technology Acceptance Model (TAM)", Computers \& Education, Vol.145, pp.1-13, 2020.

[20] N. N. I. Mohd Khajazi, "Factors that Influence Students Intention towards Using Mobile Library Services", RESEARCH HUB, Vol.2, No.3, pp.14-20, 2016.

[21] N. Aharony, "Mobile Libraries: Librarians' and Students' Perspectives," 
College and Research Libraries, Vol.75, No.2, pp.202-217, 2014.

[22] S. Paksri, “The Study of Learner's Satisfaction on Web-based Learning", Ececutive Jiurnal, Vol.33, No.4, pp.26-33, 2013.

[23] H. Rafique, "Factors Affecting Acceptance of Mobile Library Applications: Structural Equation Model", LIBRI, Vol.68, No.2, pp.99-112, .2018.

[24] F. D., Davis, R. P., Bagozzi, and P. R. Warshaw, "User Acceptance of Computer Technology: A Comparison of Two Theoretical Models. Management Science", Vol. 358, pp. 982-1003, 1989.

[25] B. Prakobtham, "Investigating the Acceptance of Social Networking in Students: Case Study of Bangkok University", Suddhiparitad, Vol.27, No.81, pp.93-108, 2011.

[26] X. Wang and others. "Factors of Mobile Library User Behavioral Intention from the Perspective of Information Ecology", The Electronic Library, Vol.36, No.4, pp.705720, 2017.

[27] W. Chaloeyprach, "Information Use Behavior and Students' Expectation to Information Services of Faculty of Liberal Arts library, Rajamangala University of Technology Thanyaburi”, Research Report, Pathum Thani: Rajamangala University of Technology Thanyaburi, 2018.

[28] A. Kaewpaitoon, “The Satisfaction Of People Toward The Service Applying The Four Sangahavatthus by Registraton Department, Muang District Office, Nakhon Sawan Province", Master'sdissertation, Mahachulalongkornrajavidyalaya University Bangkok, Thailand, 2011.

[29] S.E. Leonnard, M. Comm, and F. Thung, "The Relationship of Service Quality, Word-of mouth, and Repurchase Intention in Online Transportation Services", Journal of Process Management - New Technologies, International, Vol.5 No.4, pp.30-40, 2017. 